\title{
Design Variations on Planar Differential Antenna with Potential for Multiple, Wide, and Narrow Band Coverage
}

\author{
Domenico Pepe, ${ }^{1}$ Luigi Vallozzi, ${ }^{2}$ Hendrik Rogier, ${ }^{2}$ and Domenico Zito ${ }^{1,3}$ \\ ${ }^{1}$ Tyndall National Institute, Lee Maltings, Dyke Parade, Cork, Ireland \\ ${ }^{2}$ Department of Information Technology, Ghent University, Sint-Pietersnieuwstraat 41, 9000 Gent, Belgium \\ ${ }^{3}$ Department of Electrical and Electronic Engineering, University College Cork, College Road, Cork, Ireland
}

Correspondence should be addressed to Domenico Zito; domenico.zito@tyndall.ie

Received 31 October 2014; Revised 19 January 2015; Accepted 22 January 2015

Academic Editor: Renato Cicchetti

Copyright (C) 2015 Domenico Pepe et al. This is an open access article distributed under the Creative Commons Attribution License, which permits unrestricted use, distribution, and reproduction in any medium, provided the original work is properly cited.

\begin{abstract}
This paper presents three practical antenna implementations based on variations of one general planar differential antenna topology originally proposed for ultrawideband (UWB) applications. All designs were implemented on a low-cost FR4 substrate and experimentally characterized in an anechoic chamber. The results show how the proposed design variations lead to the required antenna performances and how they give rise to new opportunities in terms of coverage of wide, narrow, and multiple frequency bands for communication and sensing applications below $5 \mathrm{GHz}$. In particular, the results show how a significant enhancement in bandwidth performance is achieved by folding the differential radiating elements. Moreover, they show how an agile design strategy enables adaption of the antenna design to different requirements for covering wide, narrow, and multiple bands, making the proposed class of antennas suitable for different wireless applications. In detail, the proposed class of antennas covers multiple frequency bands, ranging from the $868 \mathrm{MHz}$ and $915 \mathrm{MHz}$ bands to $2.4 \mathrm{GHz}$ industrial scientific and medical (ISM) bands, including the 1.2 GHz L band for Global Positioning and Navigation Satellite Systems (GNSS) and the lower portion of the UWB band.
\end{abstract}

\section{Introduction}

Often, antenna designers develop novel antenna topologies, which are then optimized by hand for their specific applications and frequency bands. After fabricating the antenna and verifying the compliance of the performance with the requirements, additional efforts are rarely taken into account to exploit the full potential offered by the intrinsic properties of the antenna topology. In this paper, we explore the generation of novel planar antenna designs by varying the different design parameters of a well-established antenna topology. As a starting point, we consider a novel planar differential antenna that was recently proposed by our research group [1]. Such an antenna was designed to meet the design constraints, electromagnetic performance, and physical integration, required by the ultrawideband (UWB) pulse radar sensor operating approximately in the frequency band from 3 to $5 \mathrm{GHz}$. The radar sensor was implemented by cointegrating the system-on-a-chip radar transceiver with transmitting and receiving antennas on FR4 substrate $[2,3]$.
In this paper, we report for the first time the design variations of the original antenna topology, resulting in a class of antennas that cover a variety of different wide and narrow frequency bands, relevant to several wireless communication protocols. The proposed approach is validated by simulations and experimental characterizations, resulting in novel antenna prototypes that were not reported in our previous publications, which focused exclusively on the novel antenna design targeting the cointegration with the radar microchip [2-4]. In particular, we show how the design variations reflect on the antenna performance, demonstrating that the antenna topology, originated from radiating elements with a particular shape, can be adapted to generate novel prototypes that cover wide and narrow bands of interest for a number of wireless communication and sensing applications, as a consequence of variations in size and orientation of the radiating elements. The results show also how the design variations of the orientation of the two differential radiating elements can lead to a significant additional contribution to 


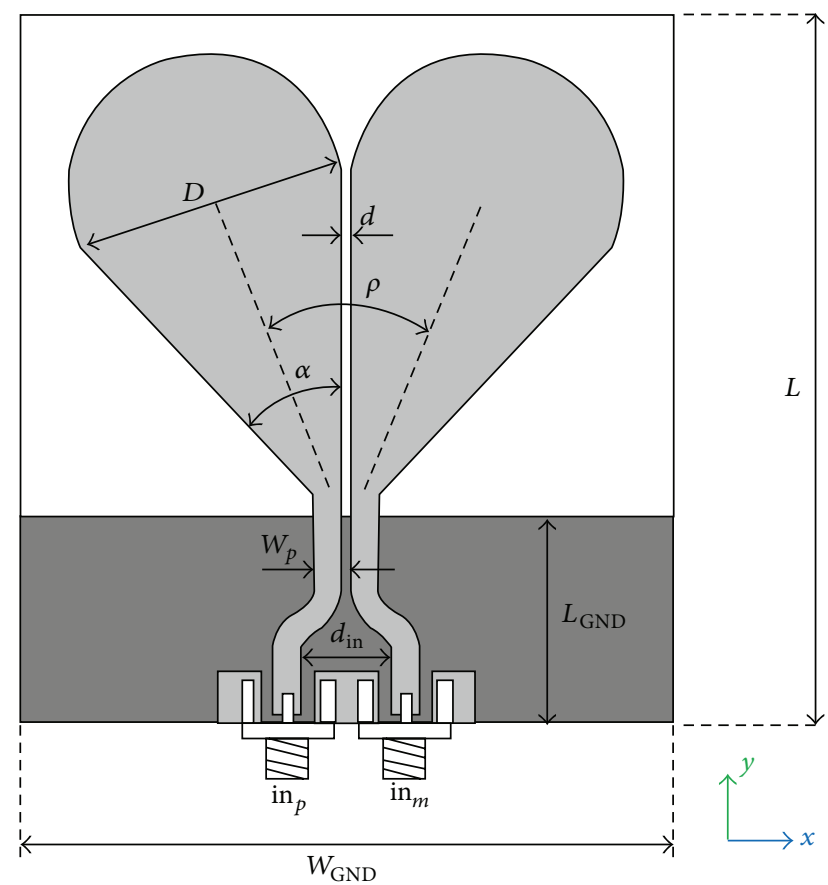

(a)

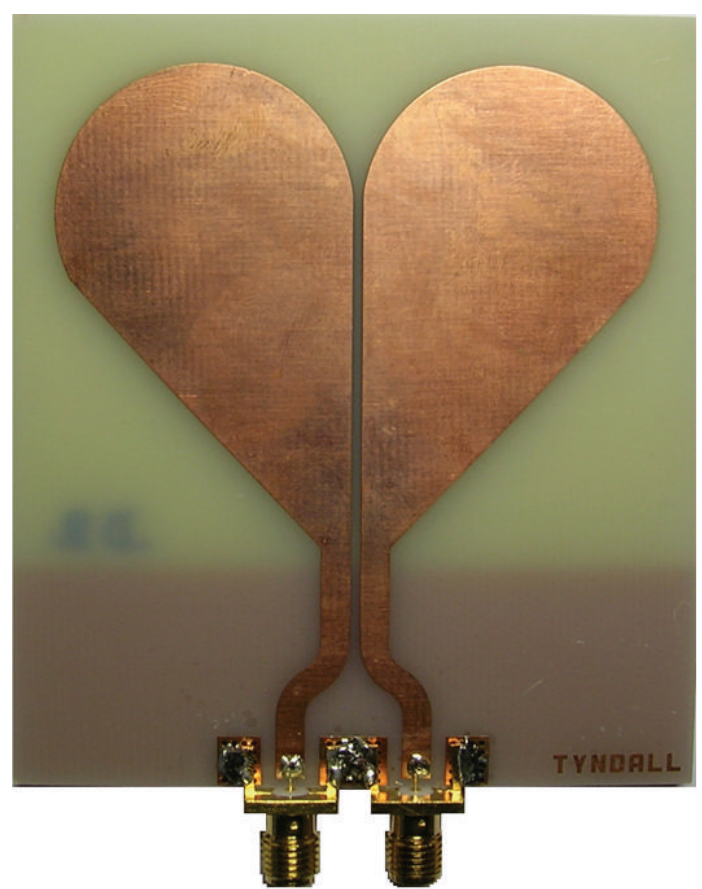

(b)

FIGURE 1: Original planar differential antenna. (a) Layout drawing in which the top copper layer is in light grey and the bottom copper layer is in dark grey. (b) Photograph of the physical implementation.

the bandwidth enhancement. This results in an additional opportunity for obtaining ultrawideband antenna performance, whereas conventional design efforts are traditionally limited to ad hoc shaping of the radiating elements, be it patches, slots, or their combinations, with circular, elliptical, rectangular, triangular, or any other ad hoc shapes, capable of providing wideband performance (e.g., [5-12]).

The paper is organized as follows. Section 2 describes the novel antenna design and summarizes, for reasons of selfconsistency, the main results obtained for the original planar differential antenna design, which serves as a useful reference for both design and performance. Section 3 reports the results of simulations and measurements obtained for the design variations of the original antenna. Finally, in Section 4, the conclusions are drawn.

\section{Planar Differential Antenna: Original Design}

The original planar differential antenna was designed on a low-cost FR4 substrate $\left(\varepsilon_{r}=4.4\right.$, dielectric thickness equal to $1.6 \mathrm{~mm}$, copper thickness of $35 \mu \mathrm{m}$, and loss tangent equal to 0.02 ) for a complete characterization as a stand-alone device, as shown in Figure 1. The antenna was simulated by means of momentum and FEM by Agilent Technologies. Each radiating element of the antenna consists of a semicircle and a triangle that provides a smooth transition towards the microchip pins [1]. The antenna terminals $\left(\mathrm{in}_{p}\right.$ and $\mathrm{in}_{m}$ in Figure 1) are designed in order to realize the appropriate feeding from the transmitter and to the receiver of the radar microchip pins $[2,3,13,14]$.

Traditionally the radiating elements of a differential antenna are pointed towards opposite directions (i.e., antipodal): here, we note that, in this novel planar differential antenna, the two radiating elements are "folded" (i.e., rotated on the antenna plane; $\rho=45$ degrees) one aside the other, resulting adjacent. The main features of this design approach are that it allows a compact design of both the transmitter and receiver antennas on the same board of the radar sensor, still maintaining good performance $[1,3]$. The distance $d$ between the two sides of the antenna is equal to $1 \mathrm{~mm}$. The diameter $D$ is equal to $3 \mathrm{~cm}$ in order to resonate at the frequency of interest (about $3 \mathrm{GHz}$ ). The aperture angle $\alpha$ of the triangle is equal to 45 degrees. The rotation angle $\rho$ between the symmetry axes of the two radiating elements is 45 degrees. Two microstrip feeding lines were added in order to allow the connection to the Vector Network Analyzer (PNA-X by Agilent Technologies) by means of planar SMA connectors (horizontal) and carry out the experimental tests. The width of the microstrip feeding lines $\left(W_{P}\right)$ is equal to $3 \mathrm{~mm}$ in order to exhibit a $50 \Omega$ characteristic impedance. The distance $d_{\text {in }}$ between the two inputs of the antenna is equal to $1 \mathrm{~cm}$ to allow the placement of two adjacent connectors, as shown in Figure 1. The characteristic sizes of the UWB antenna are reported in Table 1. Differential $S_{11}$ parameter and gain patterns were measured in an anechoic chamber by means of a linearly polarized UWB horn antenna and an automated positioning system with full rotation angle capability. The measured parameters are obtained by means 
TABLE 1: Folded planar differential antenna sizing $(D=3 \mathrm{~cm})$.

\begin{tabular}{ccccccccc}
\hline$D[\mathrm{~cm}]$ & $\alpha[\mathrm{deg}]$ & $\rho[\mathrm{deg}]$ & $d[\mathrm{~mm}]$ & $W_{p}[\mathrm{~mm}]$ & $d_{\mathrm{in}}[\mathrm{cm}]$ & $W_{\mathrm{GND}}[\mathrm{cm}]$ & $L_{\mathrm{GND}}[\mathrm{cm}]$ & $L[\mathrm{~cm}]$ \\
\hline 3 & 45 & 45 & 1 & 3 & 1 & 7.1 & 2.3 & 7.9 \\
\hline
\end{tabular}

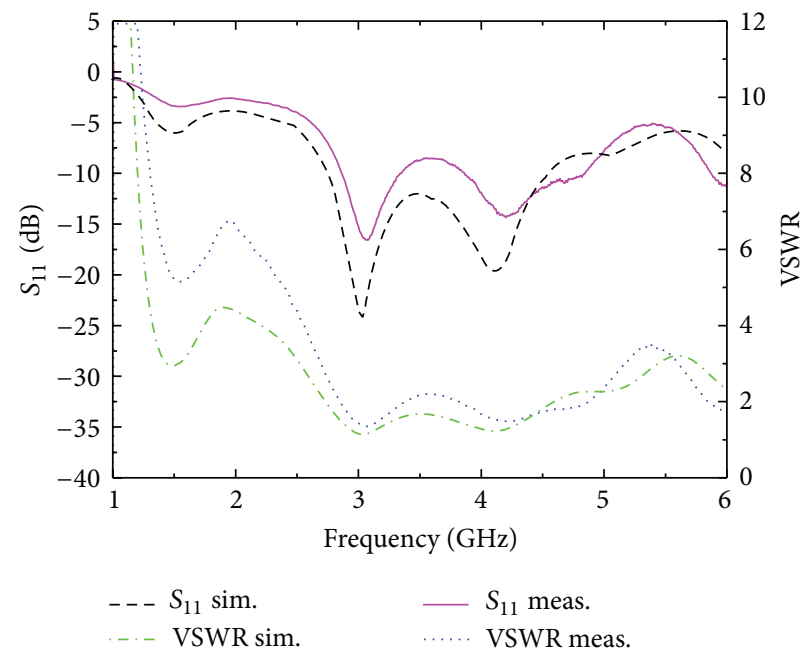

FIGURE 2: Measured and simulated $S_{11}$ and VSWR versus frequency of the original planar differential antenna with folded elements $(\rho=$ $45 \mathrm{deg} ; D=3 \mathrm{~cm})$.

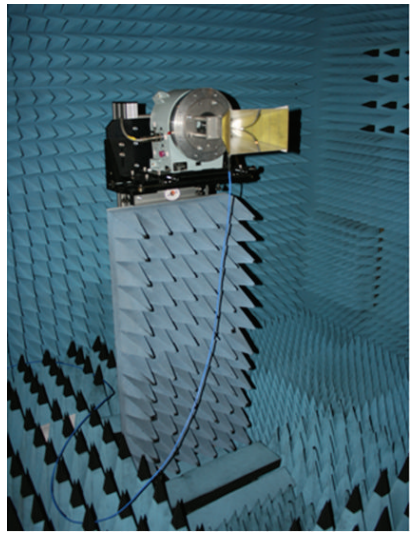

(a)

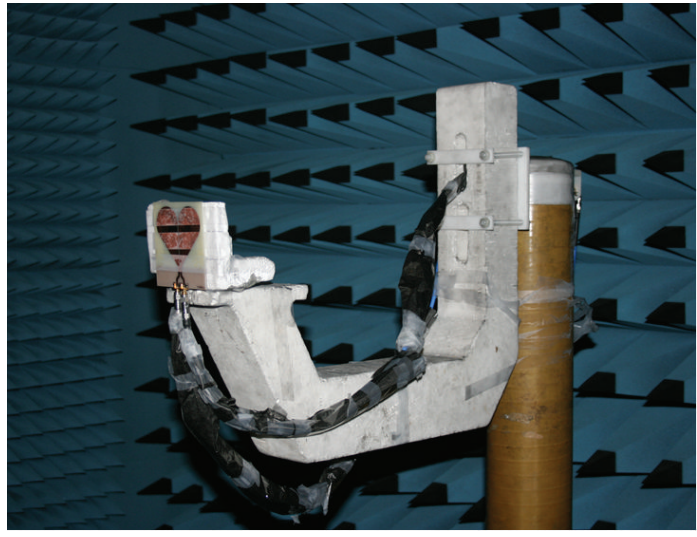

(b)

FIGURE 3: Measurement setup for the experimental characterization of the stand-alone antenna in anechoic chamber. (a) Linearly polarized UWB standard gain horn antenna. (b) Antenna under test on a rotating polystyrene arm. Measurement cables where covered with RF shielding sheets in order to reduce possible unwanted interference.

of the balanced differential measurement capabilities of the PNA-X [15] and the theory of combined differential and common-mode scattering parameters [16]. The experimental setup for the antenna patterns is shown in Figure 3.

The simulated and measured differential $S_{11}$ parameter and VSWR are reported in Figure 2. Measured $S_{11}$ exhibits a magnitude lower than $-10 \mathrm{~dB}$ in the band of interest, that is, roughly from 3 to $5 \mathrm{GHz}$. Figure 2 also reports the results for the voltage wave standing ratio (VSWR), which is lower than two over the band from 2.8 to about $4.5 \mathrm{GHz}$. The simulated and measured differential gain patterns for the $x z$ and $y z$ planes, at 3, 4, (mid-point) and $5 \mathrm{GHz}$ are shown in Figure 4. The gain is equal to about $2.4 \mathrm{dBi}$ at $4 \mathrm{GHz}$ for theta equal to 0 degrees. Figure 5 shows the near field distributions that could be useful to gain an insight of the emission [17] in the proposed antenna. The red zones identify the regions of maximum emission.

\section{Planar Differential Antennas: Design Variations}

The nominal antenna design summarized in the previous section is considered as a reference for its variations. A few effective parameter changes in the antennas topology, such as the diameter $D$ and the relative rotation angle $\rho$ of the radiating elements, have a direct impact on antenna frequency 


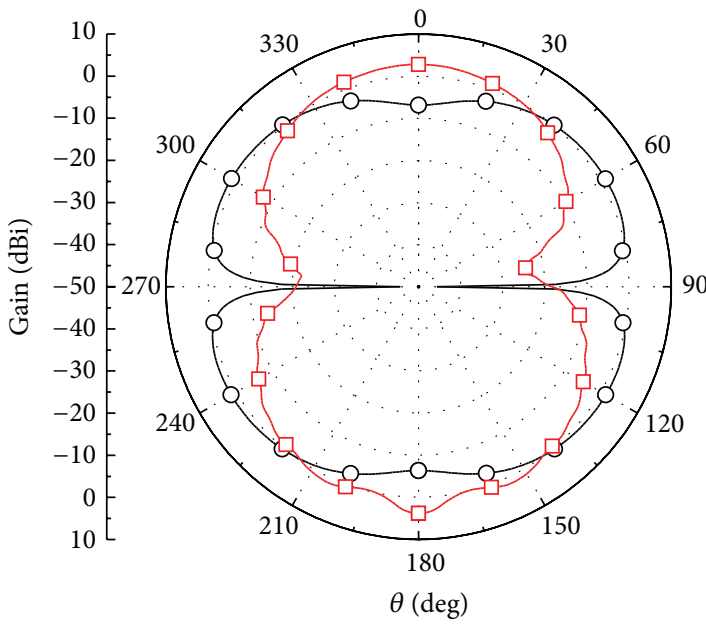

(a) $f=3 \mathrm{GHz}$ ( $x z$ plane)

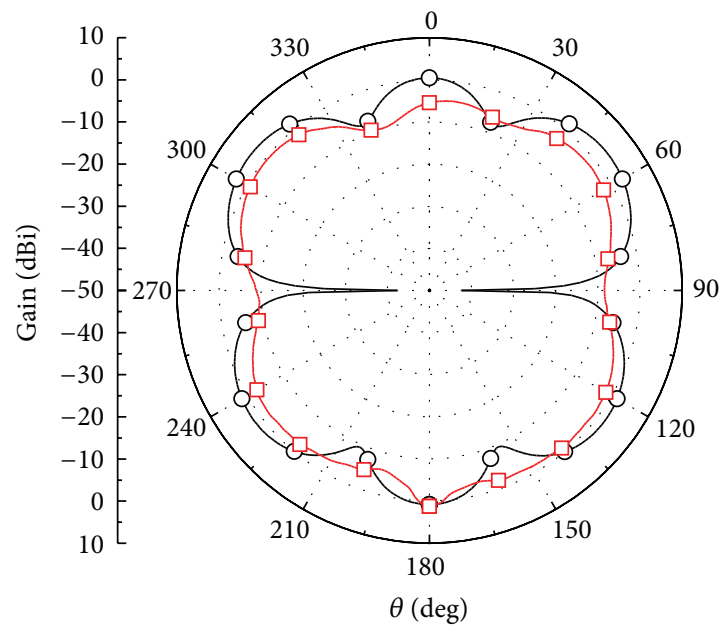

(c) $f=5 \mathrm{GHz}(x z$ plane)

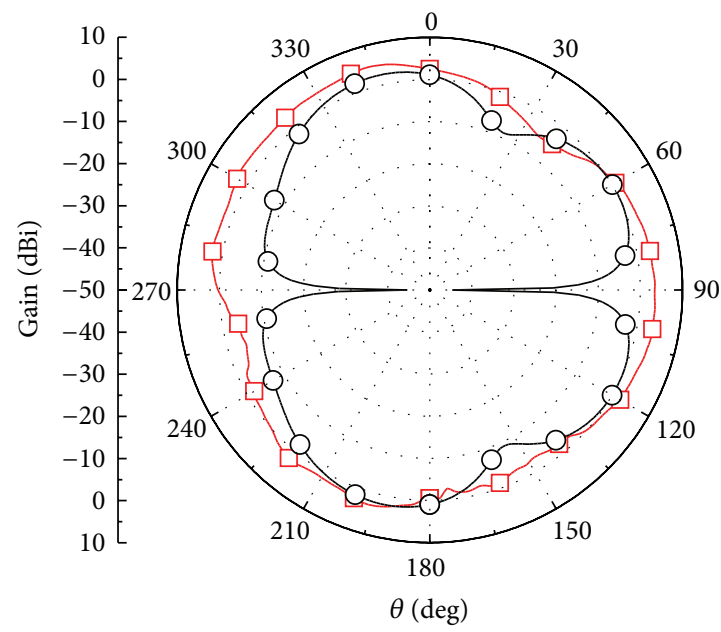

$-\mathrm{O}$ Sim.

$-\square-$ Meas.

(e) $f=4 \mathrm{GHz}(y z$ plane)

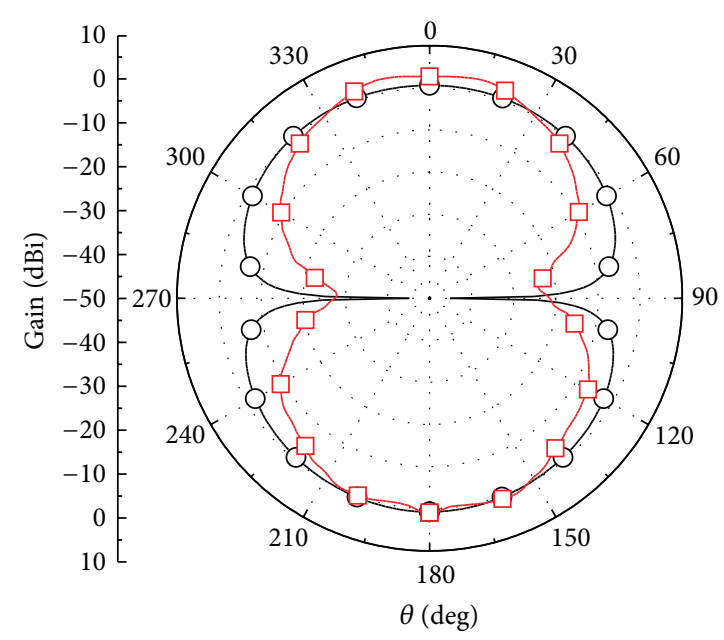

(b) $f=4 \mathrm{GHz}(x z$ plane $)$

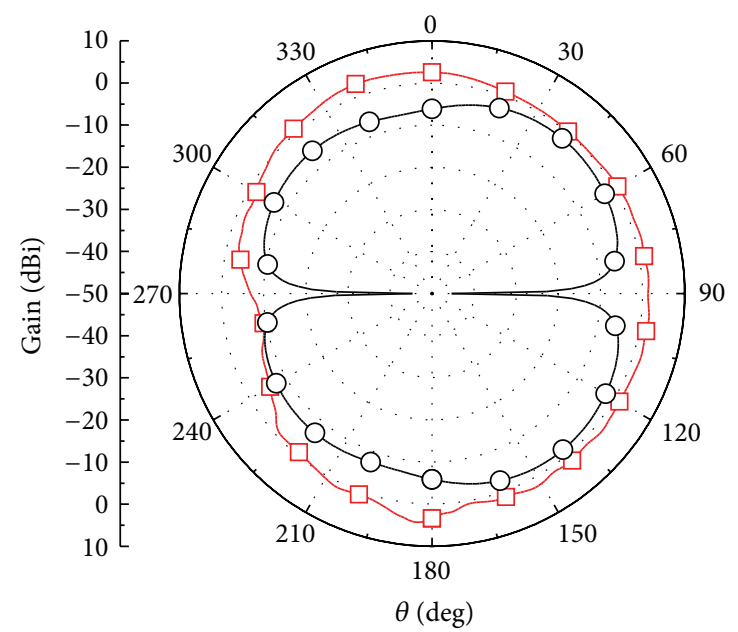

(d) $f=3 \mathrm{GHz}$ ( $y z$ plane)

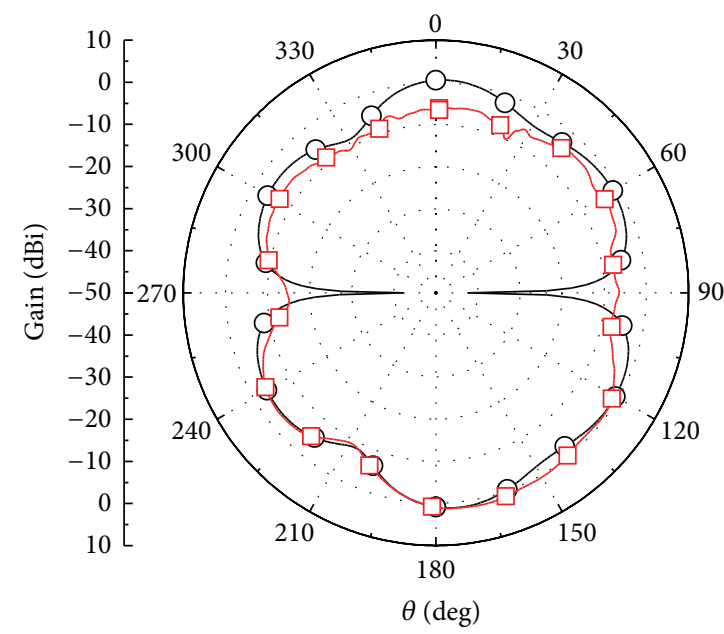

-O- Sim.

$-\square$ Meas.

(f) $f=5 \mathrm{GHz}(y z$ plane $)$

FIGURE 4: Simulated and measured gain patterns for three different frequencies $(3,4$, and $5 \mathrm{GHz})$, on $x z$ and $y z$ planes of the original differential antenna. 


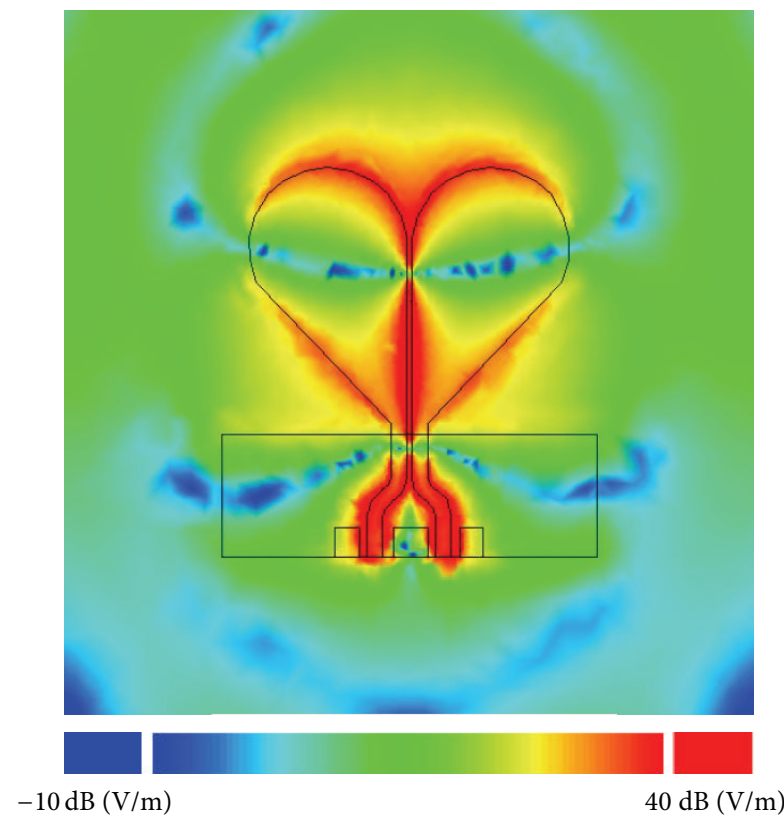

(a) $f=3 \mathrm{GHz}$

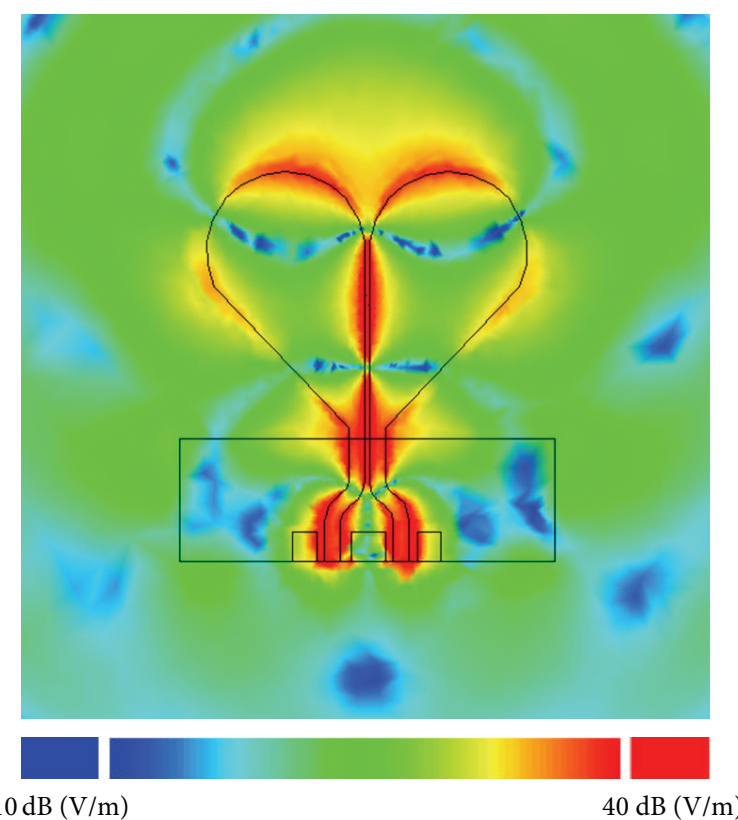

(b) $f=4 \mathrm{GHz}$

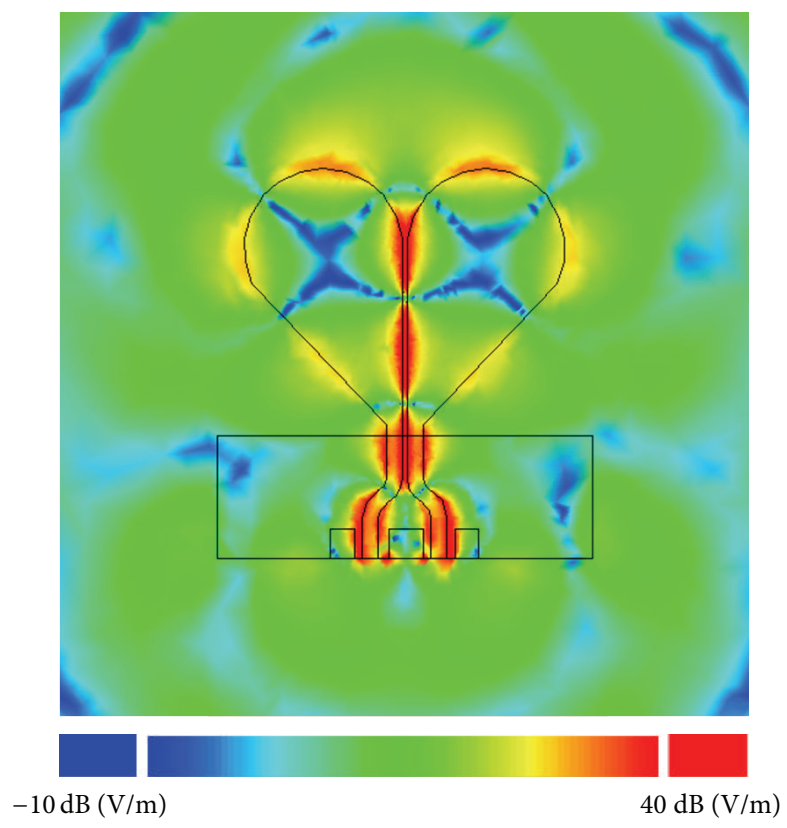

(c) $f=5 \mathrm{GHz}$

FiguRE 5: Simulated total near electric field distributions in the original antenna at the interface antenna-air for three different frequencies.

coverage. In detail, it is possible to reconfigure the antenna topology from wideband to narrowband performance, by varying the relative orientation of the two radiating lobes from $\rho=45$ degrees to $\rho=180$ degrees. Moreover, the frequency band of operation can be fine-tuned by rescaling the antenna dimensions. Such readaptation capability of the operating performance, achievable by means of agile topological variations of equal-shape radiating elements, provides new potentiality for future ad hoc designs aimed at the coverage of wide and narrow bands for some of the most widespread unlicensed applications up to 5-6 GHz. In particular, in the sequel we report the following three design variations:

$\rho=45 \mathrm{deg} ; D=4 \mathrm{~cm}$, that is, planar differential antenna with folded radiating elements ( $\rho=45 \mathrm{deg}$ ), as shown in Figure 1, but with an altered diameter $D=4 \mathrm{~cm}$.

(A) $\rho=180 \mathrm{deg} ; D=3 \mathrm{~cm}$, that is, planar differential antennas with antipodal radiating elements 


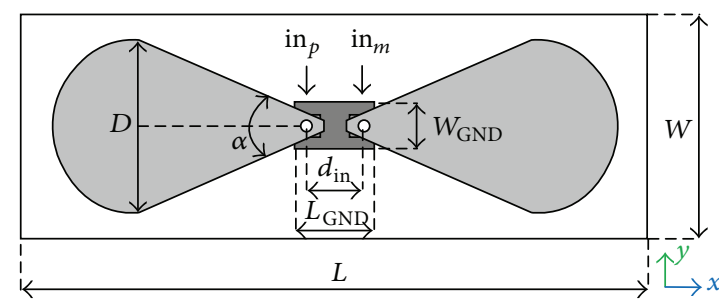

(a)

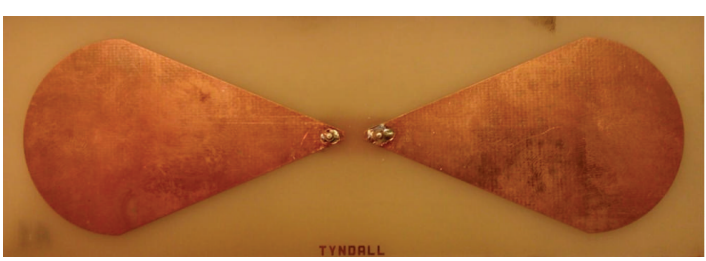

(b)

FIGURE 6: Antipodal planar differential antenna. (a) Layout drawing in which the top copper layer is in light grey and the bottom copper layer is in dark grey. (b) Photograph of the physical implementation. The two SMA connectors (vertical) are soldered on the bottom plane.

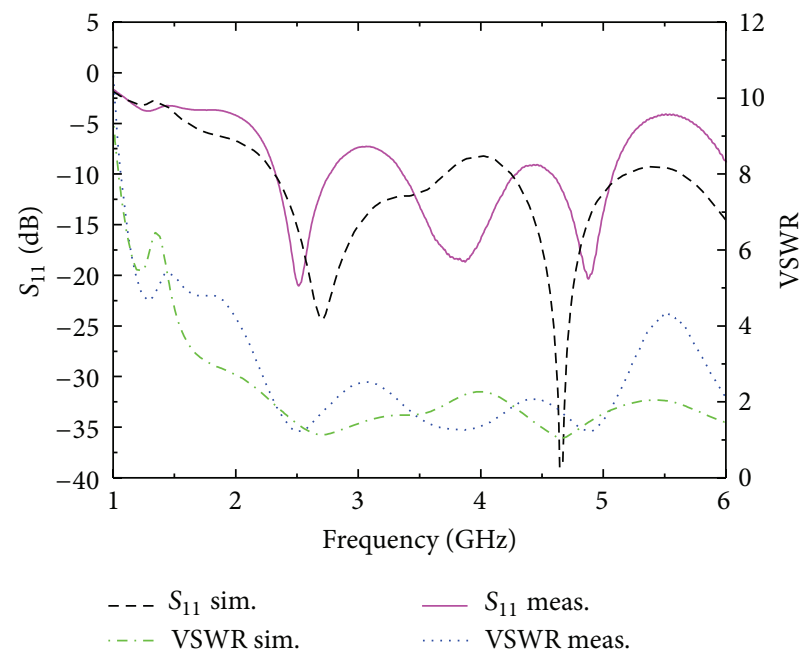

FIGURE 7: Measured and simulated differential $S_{11}$ and VSWR versus frequency of the planar differential antenna with folded radiating elements and $D=4 \mathrm{~cm}$.

$(\rho=180)$, as shown in Figure 6, and with a diameter $D=3 \mathrm{~cm}$.

(B) $\rho=180 \mathrm{deg} ; D=4 \mathrm{~cm}$, that is, planar differential antennas with antipodal radiating elements ( $\rho$ $=180$ deg), as shown in Figure 6, but with a diameter $D=4 \mathrm{~cm}$.

3.1. Folded Radiating Elements $(\rho=45 \mathrm{deg}): \mathrm{D}=4 \mathrm{~cm}$. Simulated and measured differential $S_{11}$ parameters versus frequency of the antenna with folded radiating elements ( $\rho=$ $45 \mathrm{deg} ; D=4 \mathrm{~cm}$ ) are shown in Figure 7. All the other design parameters remain unchanged.

The measurements show a reflection coefficient $S_{11}$ lower than approximately $-7.5 \mathrm{~dB}$ from 2.4 to $5 \mathrm{GHz}$.

In particular, $\left|S_{11}\right|<-10 \mathrm{~dB}$ roughly from 2.3 to $2.7 \mathrm{GHz}$ and from 3.3 to $5.1 \mathrm{GHz}$. Figure 7 also reports the simulation and measurement results for the VSWR, which is lower than two over the frequency band from about 2.3 to $2.8 \mathrm{GHz}$ and from 3.3 to $5.1 \mathrm{GHz}$. The simulated and measured antenna gain patterns for $x z$ and $y z$ planes, at 2.5, 3.75 (mid-point), and $5 \mathrm{GHz}$ are shown in Figure 8. Figure 9 reports the near electric field distributions. As expected, the results confirm that the bandwidth for this design variation with $D=4 \mathrm{~cm}$ is extended roughly by about $0.5 \mathrm{GHz}$ towards the lower frequencies with respect to the original design with $D=$ $3 \mathrm{~cm}$. This result shows that this design variation exhibits the potential for the multiband operation both for the industrial scientific medical (ISM) band at $2.4 \mathrm{GHz}[18,19]$ and the lower portion of the UWB band from about 3 to $5 \mathrm{GHz}$ $[2,13,14]$.

3.2. Antipodal Radiating Elements ( $\rho=180 \mathrm{deg}$ ): $D=$ $3 \mathrm{~cm}$. The design parameters are summarized in Table 2. The differential $S_{11}$ parameter and VSWR resulting from simulations and measurements are shown in Figure 10. $\left|S_{11}\right|$ is lower than $-10 \mathrm{~dB}$ in the frequency band from about 1.1 to $1.44 \mathrm{GHz}$. Simulated and measured antenna gain patterns for $x z$ and $y z$ planes, at $1.2 \mathrm{GHz}$, are shown in Figure 11 . The measured gain amounts to about $1.2 \mathrm{dBi}$ at $1.2 \mathrm{GHz}$ for theta equal to 0 degrees. Similar results were measured at 1.15 and $1.25 \mathrm{GHz}$. Figure 12 reports the near electric field distribution. A study on other $\rho$ and $D$ variations is reported in the Appendix.

It is also worth observing how this antenna design, generated by the radiating elements with the same shape of the UWB antenna in Figure 1, exhibits narrowband performance compatible with the coverage of the lower L band adopted by satellite applications for Global Positioning and Navigation Satellite Systems (GNSS) [20]. 


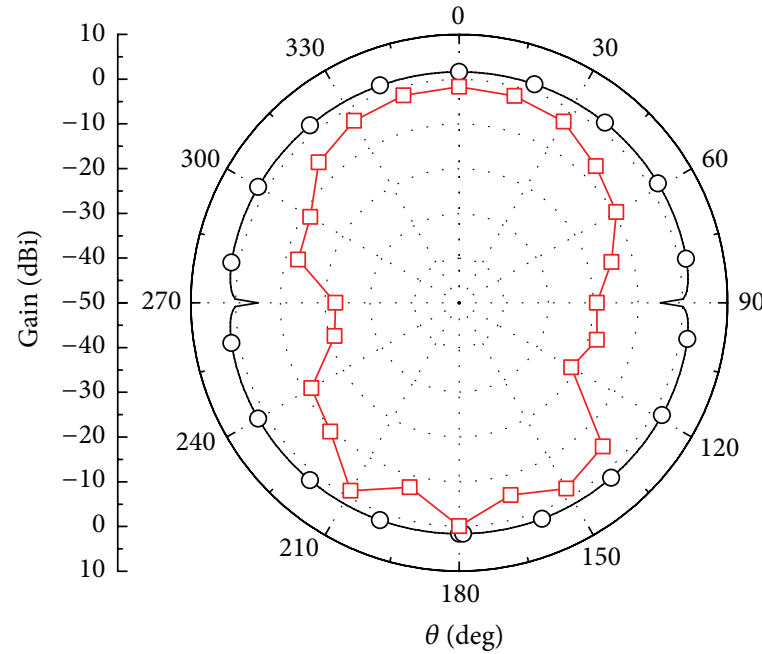

(a) $f=2.5 \mathrm{GHz}$ ( $x z$ plane)

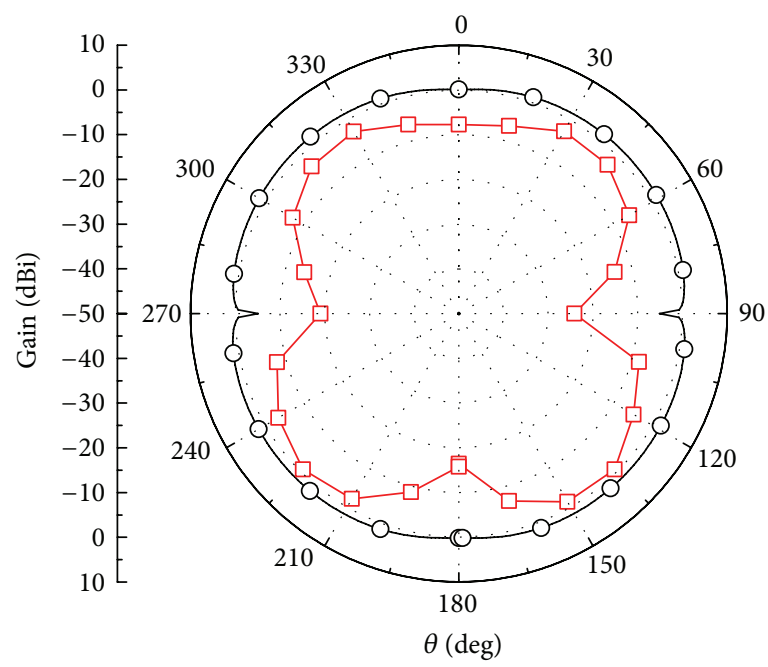

(c) $f=5 \mathrm{GHz}$ ( $x z$ plane)

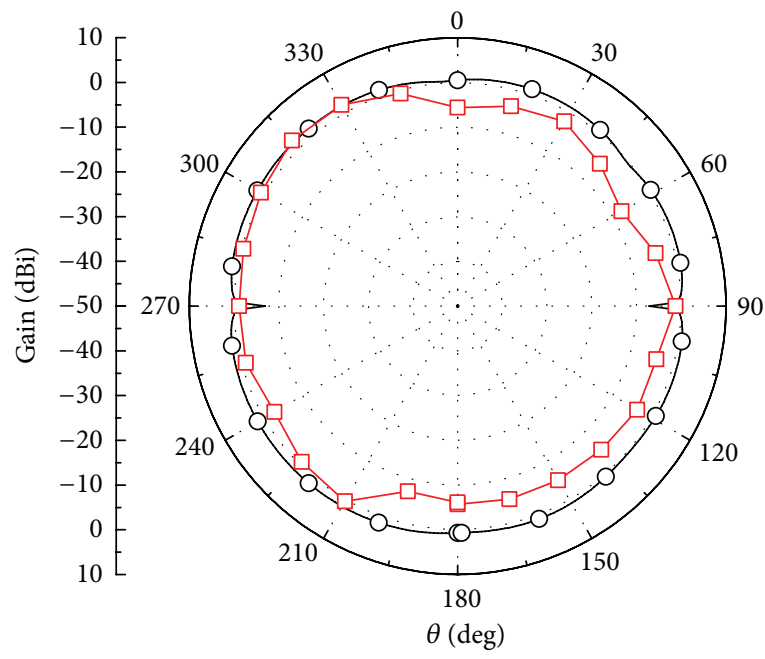

$-\mathrm{O}$ Sim.

$-\square-$ Meas.

(e) $f=3.75 \mathrm{GHz}$ ( $y z$ plane)

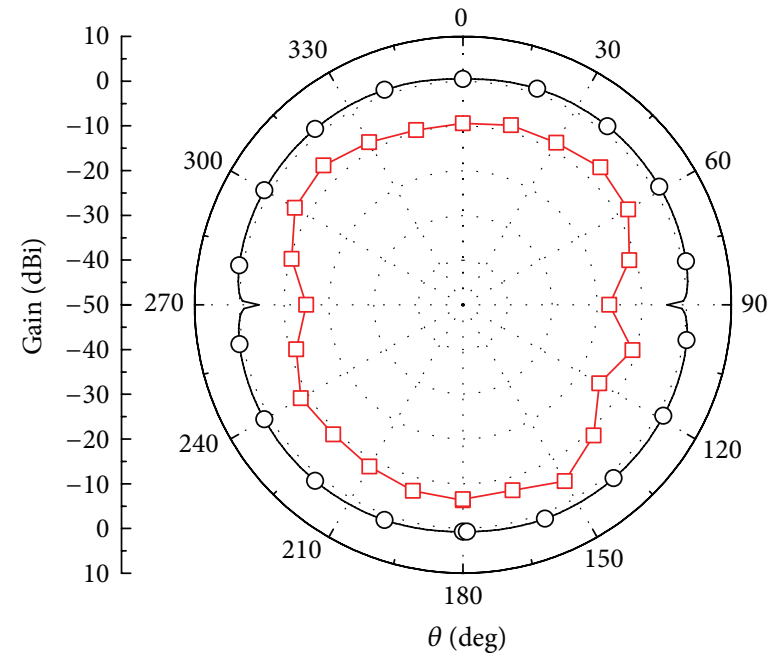

(b) $f=3.75 \mathrm{GHz}$ ( $x z$ plane)

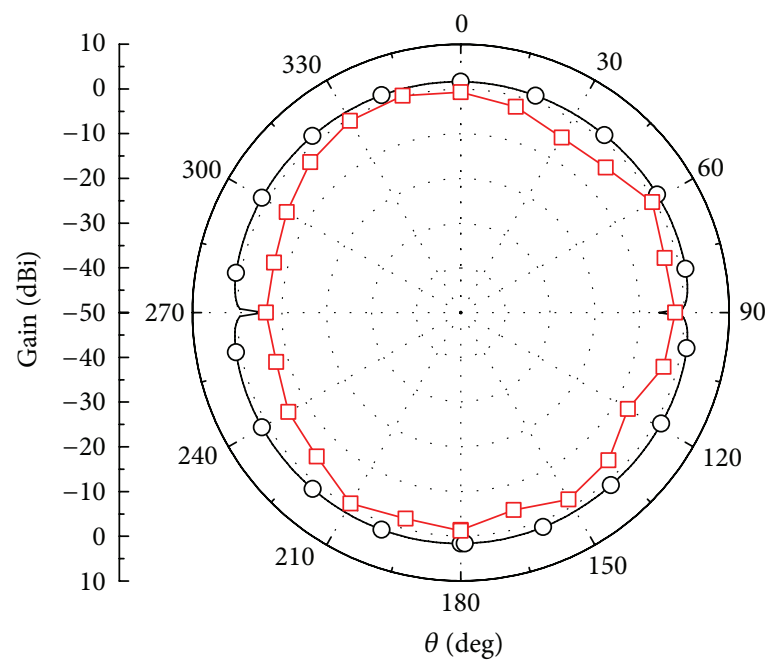

(d) $f=2.5 \mathrm{GHz}$ ( $y z$ plane)

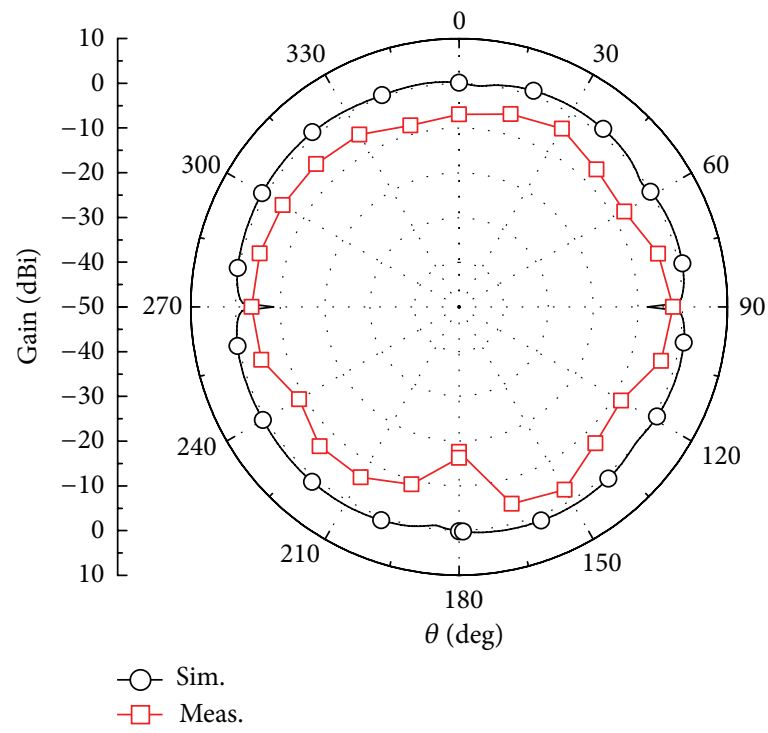

(f) $f=5 \mathrm{GHz}(y z$ plane)

FiguRE 8: Simulated and measured gain patterns for three different frequencies $(2.5,3.75$, and $5 \mathrm{GHz})$, on $x z$ and $y z$ planes of the folded antenna $(D=4 \mathrm{~cm})$. 
TABLE 2: Antipodal planar differential antenna sizing $(D=3 \mathrm{~cm})$.

\begin{tabular}{cccccccc}
\hline$D[\mathrm{~cm}]$ & $\alpha[\mathrm{deg}]$ & $\rho[\mathrm{deg}]$ & $d_{\mathrm{in}}[\mathrm{cm}]$ & $W_{\mathrm{GND}}[\mathrm{cm}]$ & $L_{\mathrm{GND}}[\mathrm{cm}]$ & $W[\mathrm{~cm}]$ & $L[\mathrm{~cm}]$ \\
\hline 3 & 45 & 180 & 1 & 0.8 & 1.4 & 4 & 11.2 \\
\hline
\end{tabular}

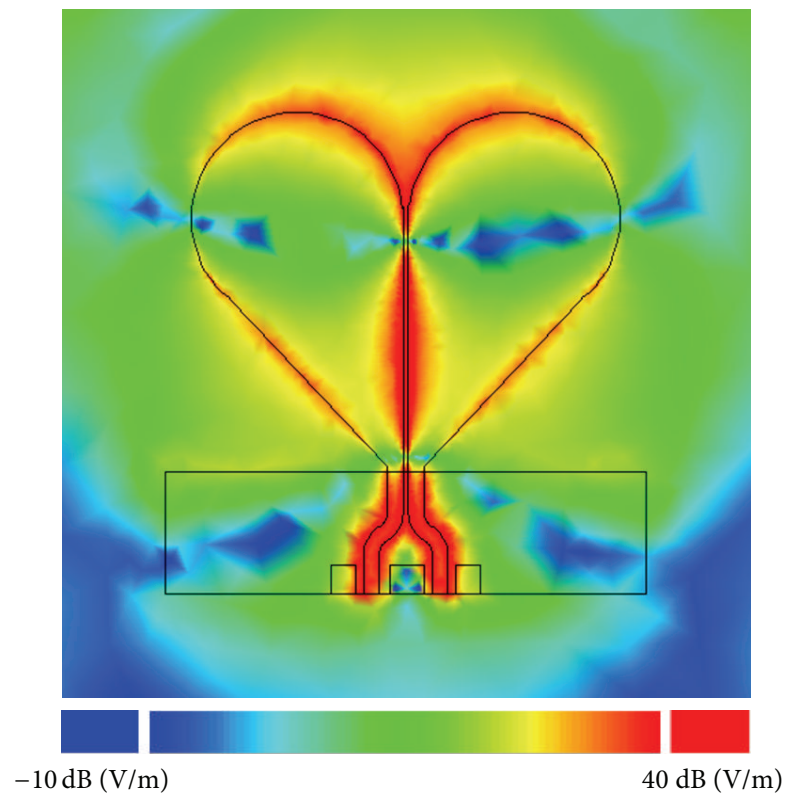

(a) $f=2.5 \mathrm{GHz}$

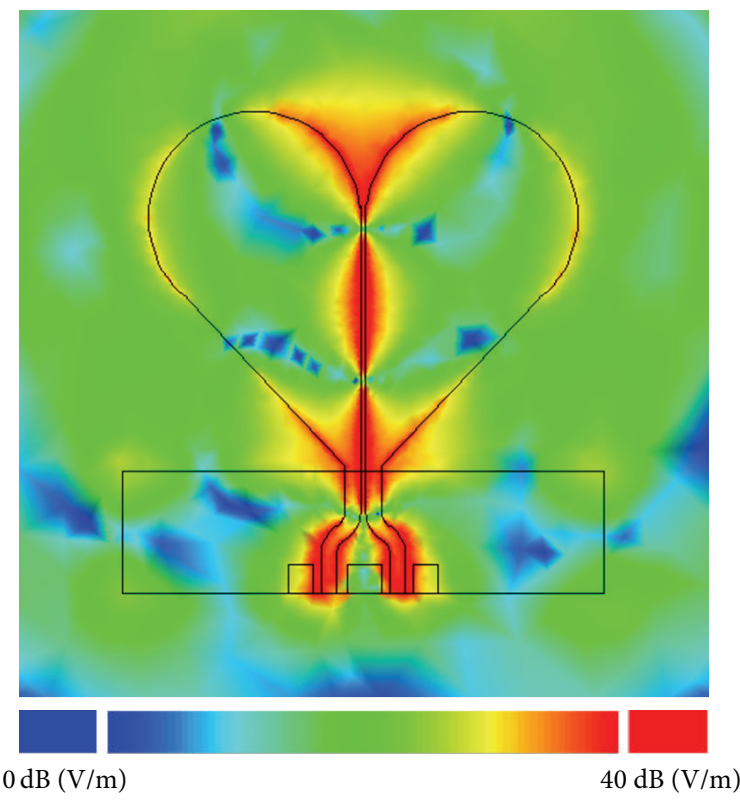

(b) $f=3.75 \mathrm{GHz}$

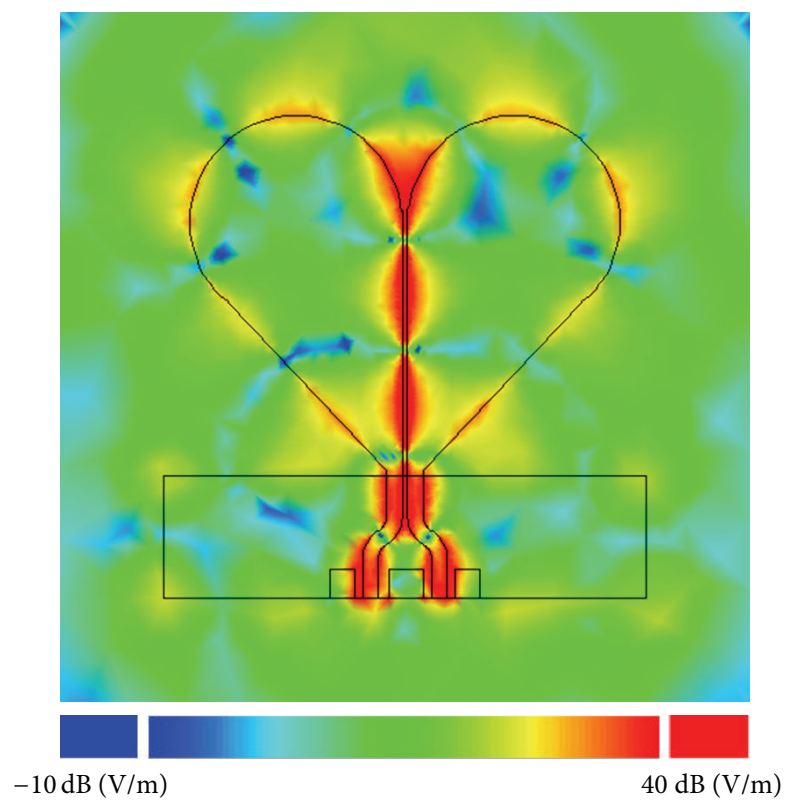

(c) $f=5 \mathrm{GHz}$

FIGURE 9: Simulated total near electric field distributions in the folded differential antenna $(D=4 \mathrm{~cm})$ at the interface antenna-air for three different frequencies.

Likewise, this result leads to the following interesting observation. Not only is the wideband operation of the folded antenna in Figure 1 due to the shape of the radiating elements, which were smoothed in order to provide a wide band operation, but also a relevant contribution is also provided by folding the radiating elements. Therefore, in addition to the research addressed to novel convenient antenna shapes, the potential offered by folding the radiating elements appears being of superior advantage with respect to those inherent in the radiating elements. Hence, this observation suggests 


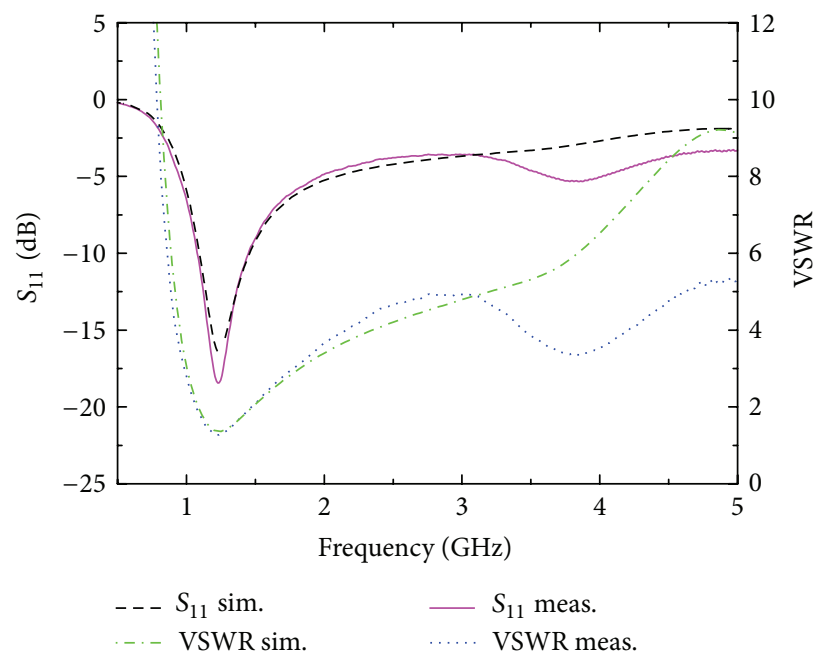

FIGURE 10: Measured and simulated $S_{11}$ and VSWR versus frequency of the planar differential antenna with antipodal radiating elements $(D=3 \mathrm{~cm})$.

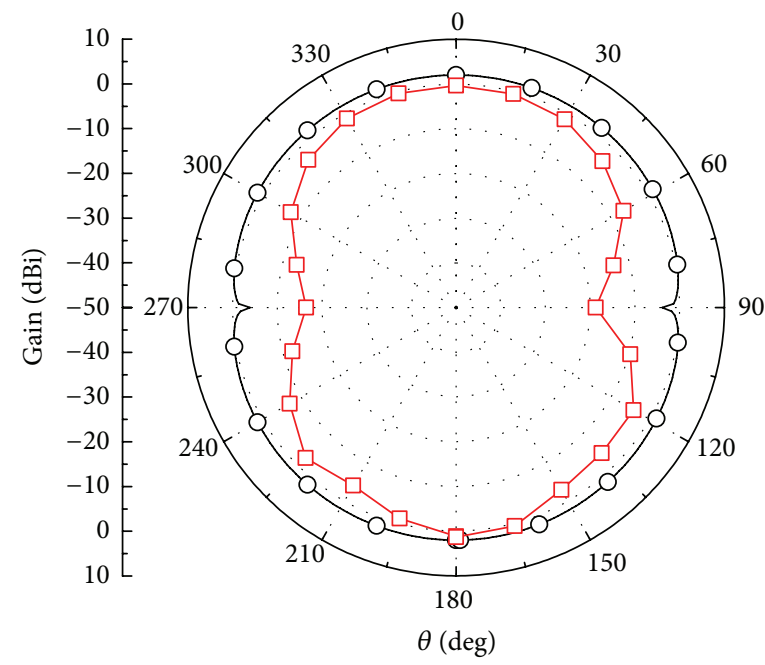

- O- Sim. $-\square-$ Meas.

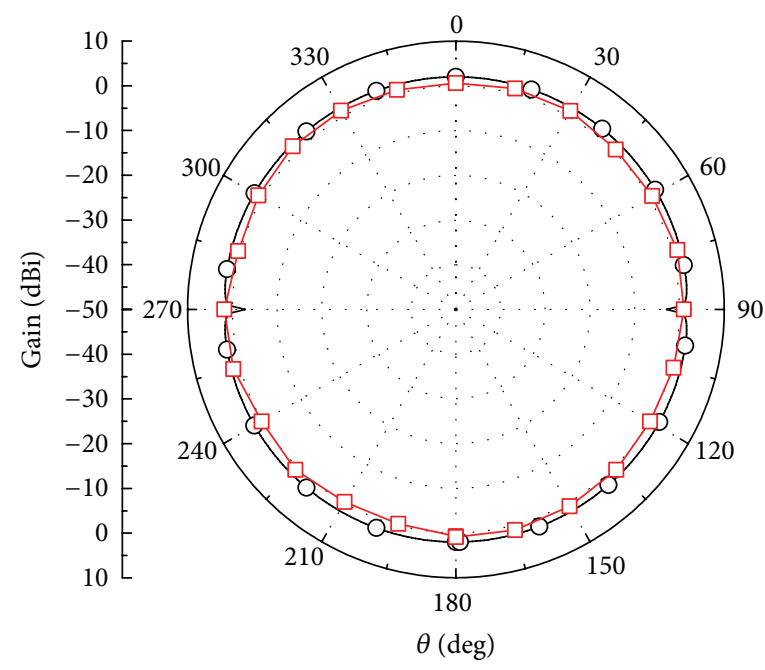

-O- Sim.

$-\square-$ Meas.

(a)

(b)

FIGURE 11: Simulated and measured gain patterns at $1.2 \mathrm{GHz}$ of the planar differential antenna with antipodal radiating elements $(D=3 \mathrm{~cm})$ : (a) $x z$ plane; (b) $y z$ plane.

new opportunities to achieve wide band operation by also exploiting the folding of the radiating elements.

3.3. Antipodal Radiating Elements $(\rho=180 \mathrm{deg}$ ): $D=4 \mathrm{~cm}$. In this design, we have $D=4 \mathrm{~cm}, L=14.6 \mathrm{~cm}$, and $W=$ $5 \mathrm{~cm}$. All the other design parameters remain unchanged with respect to those summarized for the previous case in Table 2. The $S_{11}$ parameter and VSWR resulting from simulations and measurements are shown in Figure 13. $\left|S_{11}\right|$ is lower than $-10 \mathrm{~dB}$ in the frequency band from about 0.8 to $1.06 \mathrm{GHz}$.

Simulated and measured differential antenna gain patterns at $868 \mathrm{MHz}$ for $x z$ and $y z$ planes are shown in Figure 14. The gain is equal to about $1.4 \mathrm{dBi}$ at $868 \mathrm{MHz}$, for theta equal to 0 degrees. Similar results were measured at
800 and $900 \mathrm{MHz}$. Figure 15 reports the near electric field distribution.

It is worth observing how the increase of diameter $(D=$ $4 \mathrm{~cm}$ ) with respect to the case of Figure 3 with $D=3 \mathrm{~cm}$ allows us to achieve the bandwidth performance required for the potential coverage of the ISM band at $868 \mathrm{MHz}$ [19] and also ultrahigh frequency (UHF) band at $915 \mathrm{MHz}$ for radiofrequency identification (RFID) [21, 22].

As already noted in the previous subsection, it is worth observing once again how the folding of the radiating elements as in Figure 3 ( $\rho=45 \mathrm{deg}$ ) leads to an extension of the operation bandwidth with respect to this design case. In particular, by folding the two radiating elements with $D=4 \mathrm{~cm}$, we obtain in this case multiple bands, which provide coverage 


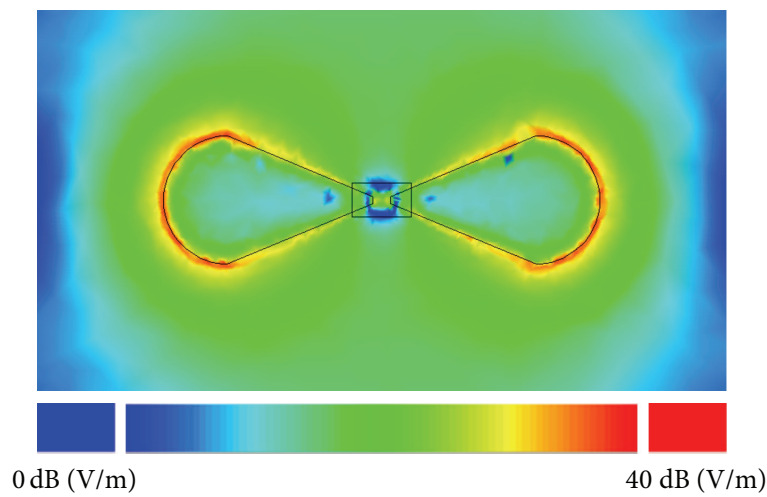

FIGURE 12: Simulated total near electric field distribution in the planar antipodal antenna $(D=3 \mathrm{~cm})$ at the interface antenna-air for $1.2 \mathrm{GHz}$.

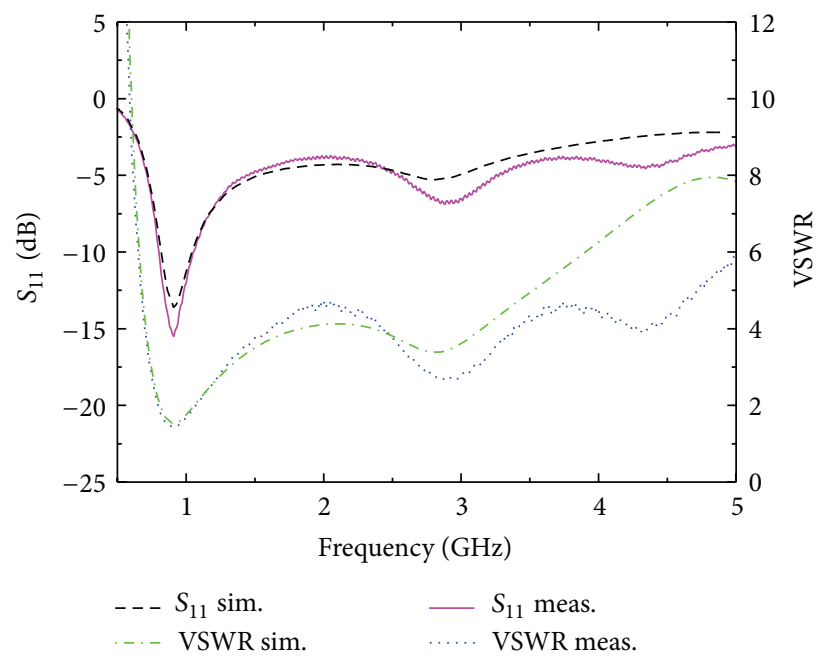

FIGURE 13: Measured and simulated differential $S_{11}$ and VSWR versus frequency of the planar differential antenna with antipodal radiating elements $(D=4 \mathrm{~cm})$.

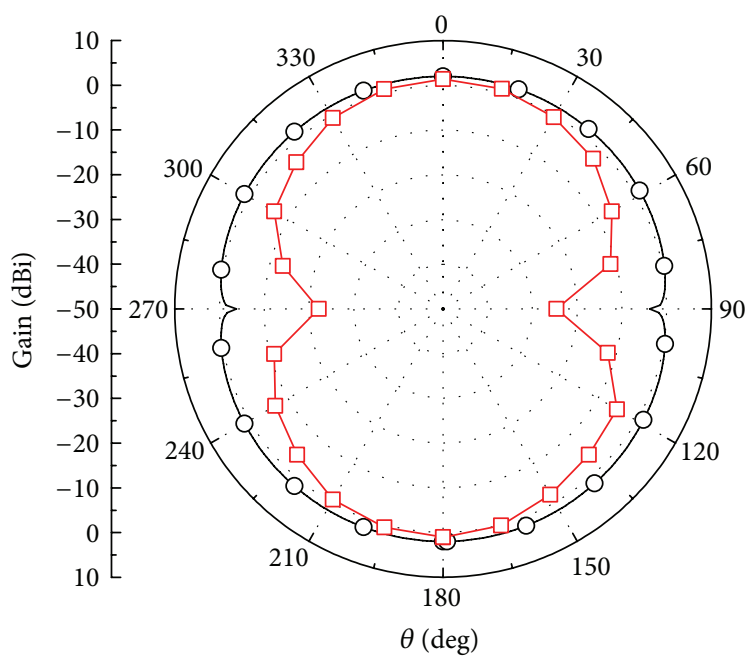

-O- Sim.

$-\square-$ Meas.

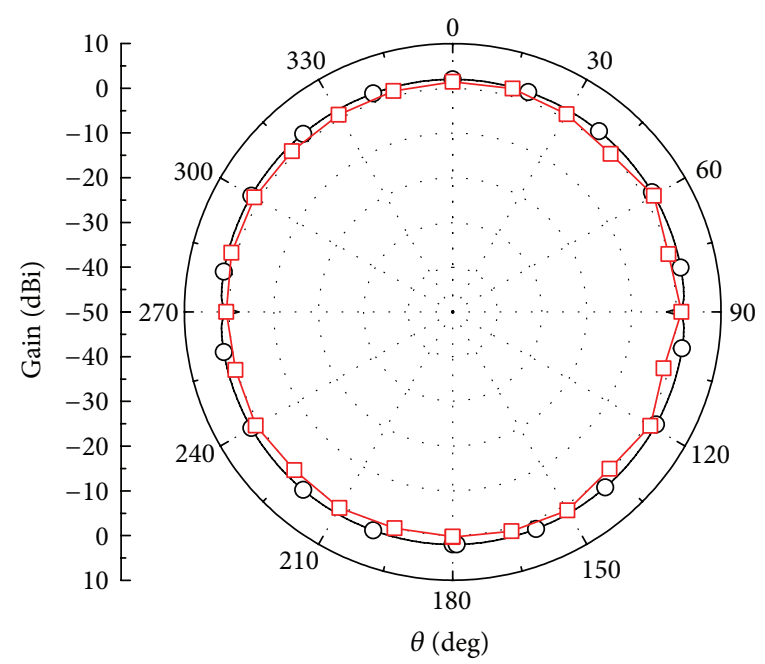

-O- Sim.

$-\square-$ Meas.

(a)

(b)

FiguRE 14: Simulated and measured differential gain patterns at $868 \mathrm{MHz}$ of the antipodal planar differential antenna $(D=4 \mathrm{~cm}):(\mathrm{a}) x z$ plane; (b) $y z$ plane. 


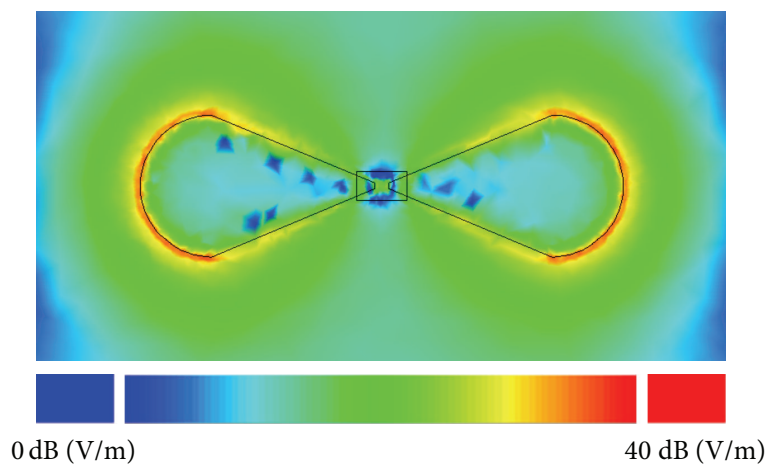

FiguRE 15: Simulated total near electric field distribution in the antipodal planar differential antenna $(D=4 \mathrm{~cm})$ at the interface antenna-air for $868 \mathrm{MHz}$.

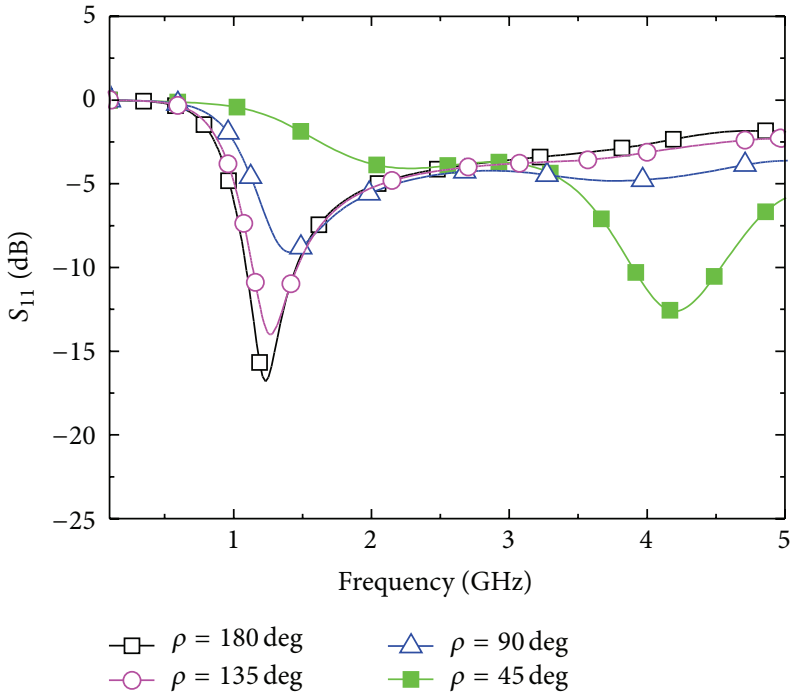

(a)

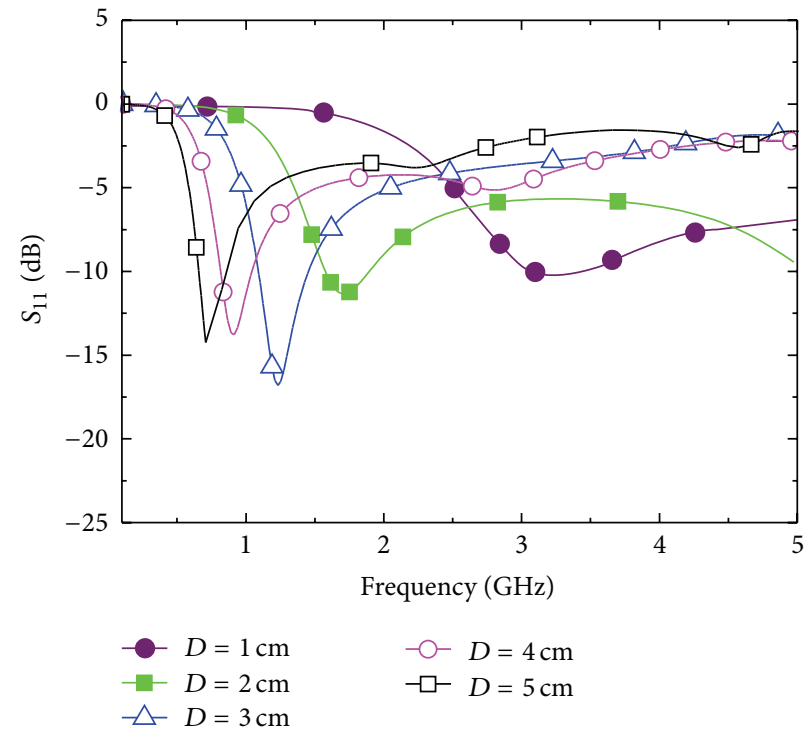

(b)

FIGURE 16: Simulated differential $S_{11}$ versus frequency of the planar differential antenna as effect of variations on $\rho$ and $D$ : (a) $D=3 \mathrm{~cm}$; (b) $\rho=180 \mathrm{deg}$.

of the $2.4 \mathrm{GHz}$ ISM band and the lower portion (about 3$5 \mathrm{GHz}$ ) of the UWB band.

This last interesting aspect could be exploited for the implementation of reconfigurable single-antenna single-chip transmitters, or receivers, characterized by highly reusable building blocks [23] and capable of operating over multiple bands, be it narrow and wide bands, both for communication and sensing applications [24].

\section{Conclusions}

A new class of planar differential antennas is presented through the design variations of a recently proposed planar differential antenna enabling the cointegration with a microchip radar sensor. All the designs were implemented on FR4 substrate and validated through experimental measurements.

This study allowed the exploration of the antenna performance and its sensitivity to design variations, their impact on performance, and the opportunities for their potential future exploitations through ad hoc designs for a number of communication and sensing applications below $5 \mathrm{GHz}$.

In particular, the results show how folding the radiating elements allows a significant bandwidth enhancement, even larger than the opportunities deriving from the intrinsic properties of the radiating element itself, as exhibited in the case of antipodal routing.

The new opportunities emerging from this study suggest also the possibility of further developing and implementing an agile design strategy, highly readaptable to specific needs and that, thereby, could be applied to a number of cases and applications.

Overall, the results show that the design variations originated from the same shape of the radiating elements, be it folded or antipodal design variations, exhibit a good potential for covering wide, narrow, and multiple bands, ranging from those allocated in the ISM frequency band $868 \mathrm{MHz}$ and UHF at $915 \mathrm{MHz}$ and $2.4 \mathrm{GHz}$ band, as well as 


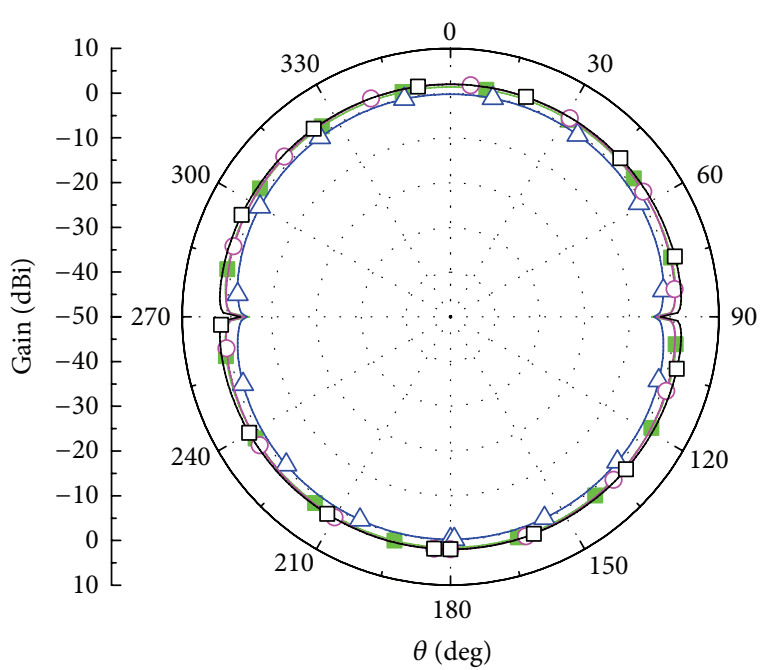

$\begin{array}{ll}-\rho=45 \mathrm{deg}, f=4.2 \mathrm{GHz} & -\bigcirc-\rho=135 \mathrm{deg}, f=1.3 \mathrm{GHz} \\ -\triangle \rho=90 \mathrm{deg}, f=1.4 \mathrm{GHz} & \square-\rho=180 \mathrm{deg}, f=1.2 \mathrm{GHz}\end{array}$

(a)

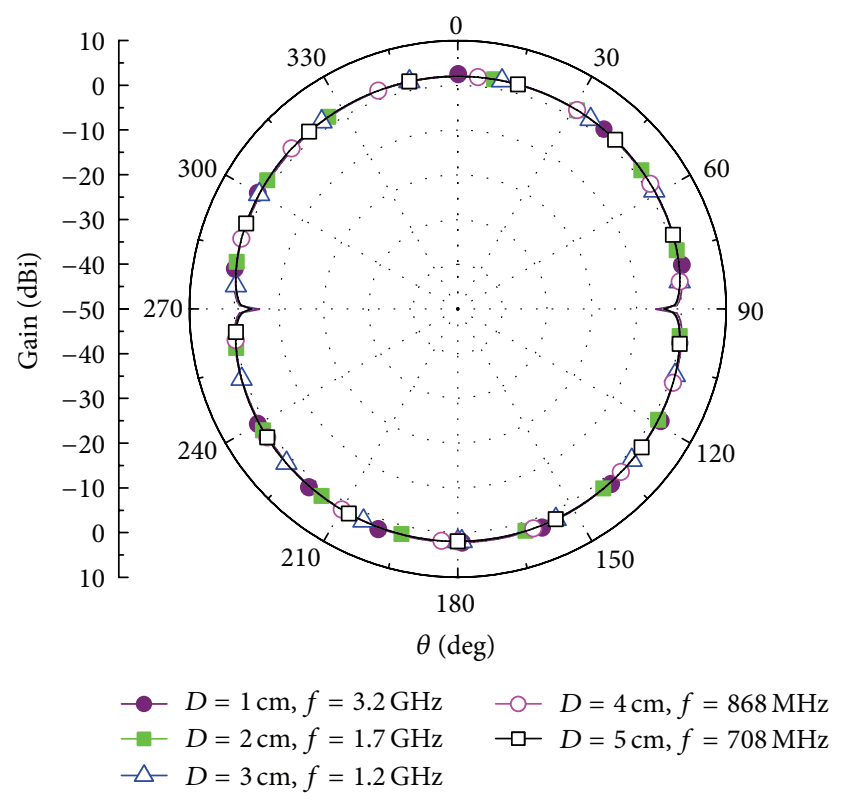

(c)

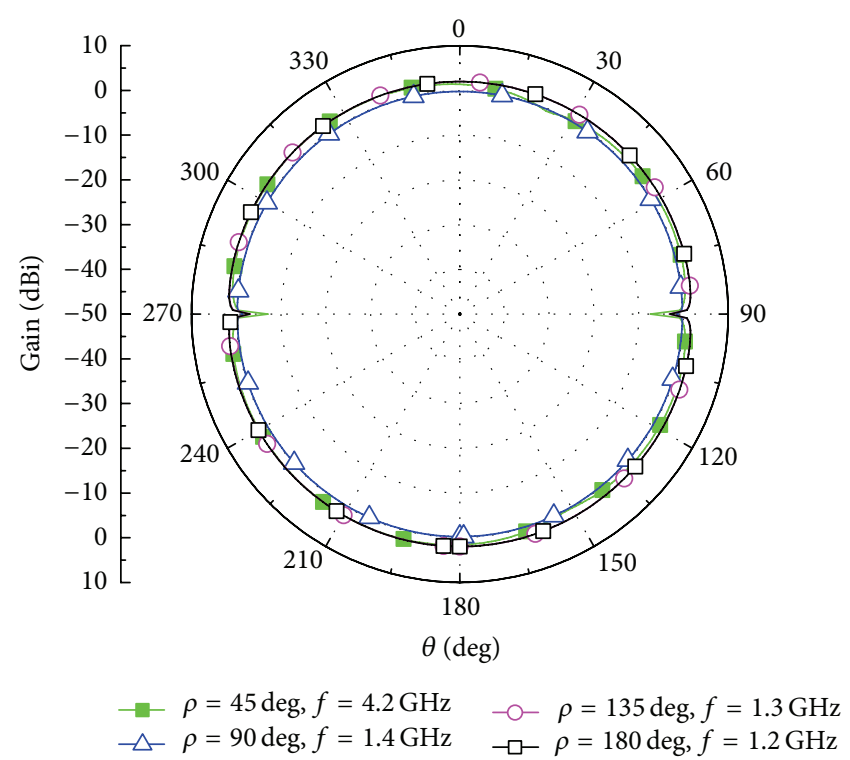

(b)

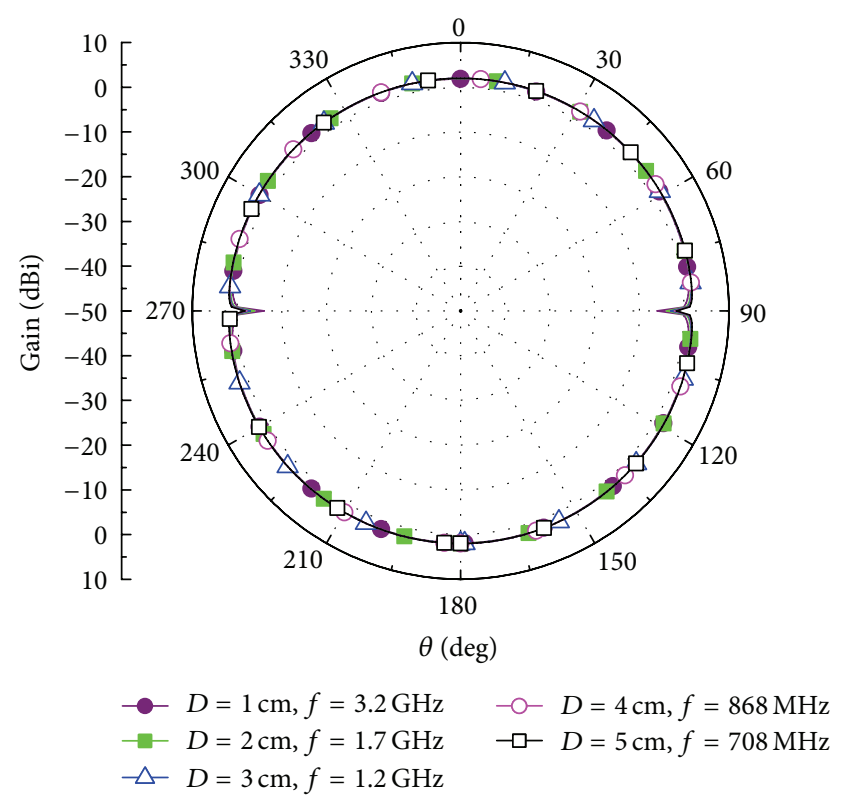

(d)

FIGURE 17: Simulated gain patterns of the planar differential antenna at the frequency of minimum return loss as effect of variations on $\rho$ and $D$ : (a) $D=3 \mathrm{~cm}, x z$ plane; (b) $D=3 \mathrm{~cm}, y z$ plane; (c) $\rho=180 \mathrm{deg}, x z$ plane; (d) $\rho=180 \mathrm{deg}, y z$ plane.

in the lower $\mathrm{L}$ band at $1.2 \mathrm{GHz}$ and the lower portion of the UWB band. This potential enables their exploitation also for the implementation of multimode multiband reconfigurable radiofrequency transceivers expected for emerging and long term evolution wireless applications.

\section{Appendix}

In Figures 16 and 17, we report the results of a parametric study of the antenna in Figure 6, obtained by varying the parameters $\rho(45,90,135$, and $180 \mathrm{deg})$ and $D(1,2,3,4$, and $5 \mathrm{~cm}$ ), in order to show the effects of the parametric variation on the return loss and gain.

\section{Conflict of Interests}

The authors declare that there is no conflict of interests regarding the publication of this paper.

\section{Acknowledgments}

The authors are grateful to Agilent (now Keysight) Technologies and Microlease for their generous donations of hardware equipment and software computer-aided design tools in support of the research activities carried out at the Marconi Lab established and led by Professor Domenico Zito. This work was supported by the Science Foundation 
Ireland (SFI), the Irish Research Council (IRC), and Higher Education Authority (HEA).

\section{References}

[1] D. Pepe, L. Vallozzi, H. Rogier, and D. Zito, "Planar differential antenna for short-range UWB pulse radar sensor," IEEE Antennas and Wireless Propagation Letters, vol. 12, pp. 1527-1530, 2013.

[2] D. Zito, D. Pepe, M. Mincica et al., "SoC CMOS UWB pulse radar sensor for contactless respiratory rate monitoring," IEEE Transactions on Biomedical Circuits and Systems, vol. 5, no. 6, pp. 503-510, 2011.

[3] D. Zito and D. Pepe, "Planar differential antenna design and integration with pulse radar microchip sensor," IEEE Sensors Journal, vol. 14, no. 8, pp. 2477-2487, 2014.

[4] D. Zito and D. Pepe, "Monitoring respiratory pattern in adult and infant via contactless detection of thorax and abdomen movements through SoC UWB pulse radar sensor," in Proceedings of the IEEE Topical Conference on Biomedical Wireless Technologies, Networks, and Sensing Systems (BioWireleSS '14), pp. 1-3, Newport Beach, Calif, USA, January 2014.

[5] J. D. S. Langley, P. S. Hall, and P. Newham, "Balanced antipodal Vivaldi antenna for wide bandwidth phased arrays," IEE Proceedings Microwaves, Antennas and Propagation, vol. 143, no. 2, pp. 97-102, 1996.

[6] J. Liang, C. C. Chiau, X. Chen, and C. G. Parini, "Study of a printed circular disc monopole antenna for UWB systems," IEEE Transactions on Antennas and Propagation, vol. 53, no. 11, pp. 3500-3504, 2005.

[7] J. R. Verbiest and G. A. E. Vandenbosch, "Small-size planar triangular monopole antenna for UWB WBAN applications," Electronics Letters, vol. 42, no. 10, pp. 566-567, 2006.

[8] J. R. Kelly, P. S. Hall, and P. Gardner, "Planar band-notched UWB antenna," in Proceedings of the 3rd European Conference on Antennas and Propagation (EuCAP '09), pp. 1636-1639, March 2009.

[9] K. Bahadori and Y. Rahmat-Samii, "An elliptic-card UWB antenna for wireless communications," in Proceedings of the European Conference on Antennas and Propagation (EuCAP '06), pp. 1-4, November 2006.

[10] G. Cappelletti, D. Caratelli, R. Cicchetti, and M. Simeoni, "A low-profile printed drop-shaped dipole antenna for wideband wireless applications," IEEE Transactions on Antennas and Propagation, vol. 59, no. 10, pp. 3526-3535, 2011.

[11] K. Vembarasi, S. Soumini, P. Vinothini, and G. Vijayalakshmy, "Bi-circular UWB differential antenna for wideband coverage," International Journal of Advanced Engineering and Global Technology, vol. 2, no. 3, pp. 552-555, 2014.

[12] I. E. Lager, L. P. Ligthart, D. P. Tran et al., "The relativity of bandwidth - the pursuit of truly ultra wideband radiators for communication applications," in Proceedings of the 8th International Conference on Communications (COMM '10), pp. 7-14, IEEE, Bucharest, Romania, June 2010.

[13] F. Zito, D. Pepe, and D. Zito, "UWB CMOS monocycle pulse generator," IEEE Transactions on Circuits and Systems. I. Regular Papers, vol. 57, no. 10, pp. 2654-2664, 2010.

[14] D. Pepe and D. Zito, " $22.7 \mathrm{~dB}$ gain $-19.7 \mathrm{dBm}$ iCP1dB UWB CMOS LNA," IEEE Transactions on Circuits and Systems II: Express Briefs, vol. 56, no. 9, pp. 689-693, 2009.

[15] Agilent Technologies, "Concepts in balanced device measurements," Application Note 1373-2, Multiport \& Balanced Device Measurement Application Note Series, 2002.
[16] D. E. Bockelman and W. R. Eisenstadt, "Combined differential and common-mode scattering parameters: theory and simulation," IEEE Transactions on Microwave Theory and Techniques, vol. 43, no. 7, pp. 1530-1539, 1995.

[17] D. Caratelli, R. Cicchetti, G. Bit-Babik, and A. Faraone, "Circuit model and near-field behavior of a novel patch antenna for WWLAN applications," Microwave and Optical Technology Letters, vol. 49, no. 1, pp. 97-100, 2007.

[18] X. Quan, R. Li, Y. Cui, and M. M. Tentzeris, "Analysis and design of a compact dual-band directional antenna," IEEE Antennas and Wireless Propagation Letters, vol. 11, pp. 547-550, 2012.

[19] C. Feránndez-Prades, H. Rogier, A. Collado, and M. M. Tentzeris, "Flexible substrate antennas," International Journal of Antennas and Propagation, vol. 2012, Article ID 746360, 2 pages, 2012.

[20] A. Dierck, H. Rogier, and F. Declercq, "A wearable active antenna for global positioning system and satellite phone," IEEE Transactions on Antennas and Propagation, vol. 61, no. 2, pp. 532-538, 2013.

[21] C. M. Kruesi, R. J. Vyas, and M. M. Tentzeris, "Design and development of a novel 3-D cubic antenna for wireless sensor networks (WSNs) and RFID applications," IEEE Transactions on Antennas and Propagation, vol. 57, no. 10, pp. 3293-3299, 2009.

[22] F. Alimenti, M. Virili, G. Orecchini et al., "A new contactless assembly method for paper substrate antennas and UHF RFID chips," IEEE Transactions on Microwave Theory and Techniques, vol. 59, no. 3, pp. 627-637, 2011.

[23] G. Hueber and R. B. Staszewski, Multi-Mode/Multi-Band RF Transceivers for Wireless Communications: Advanced Techniques, Architectures, and Trends, Wiley-IEEE Press, 2011.

[24] D. Zito and D. Pepe, "UWB pulse radio transceivers and antennas: considerations on design and implementation," in Proceedings of the 8th European Conference on Antennas and Propagation (EuCAP '14), pp. 1633-1637, The Hague, The Netherlands, April 2014. 

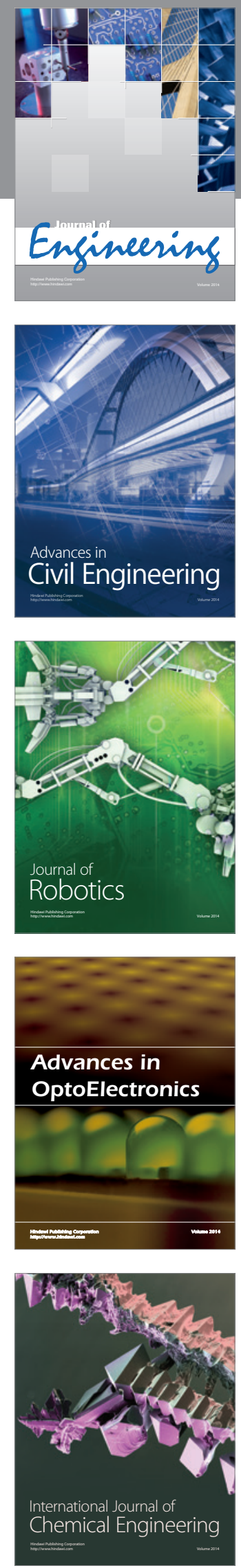

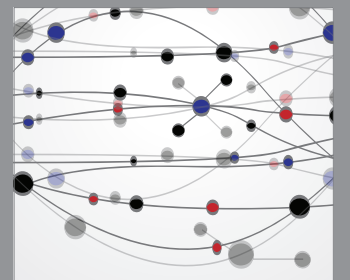

The Scientific World Journal
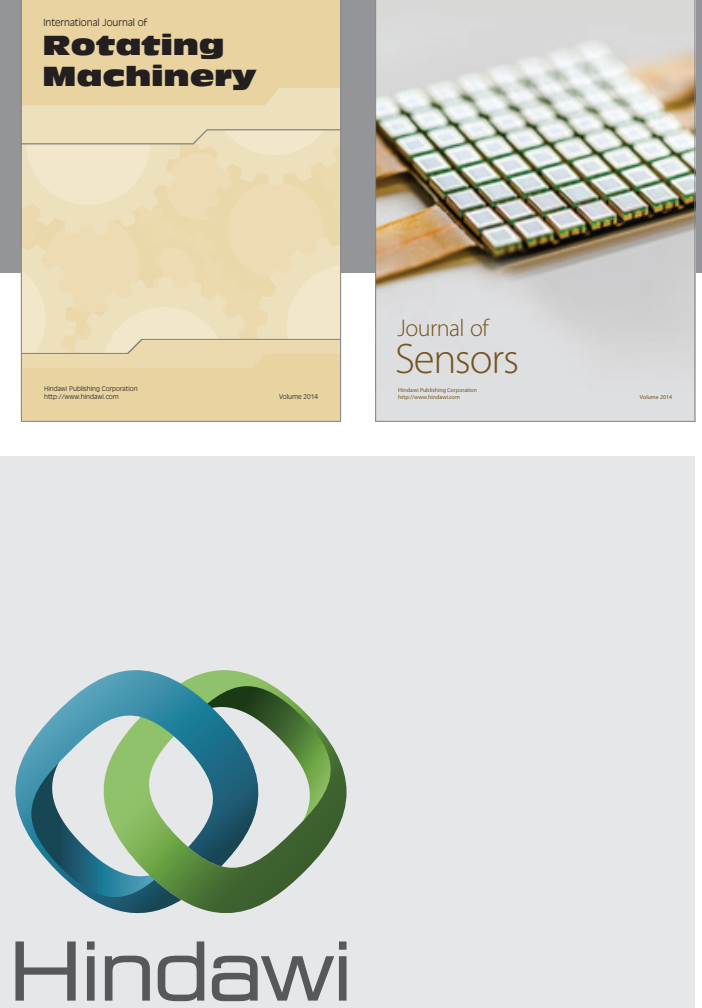

Submit your manuscripts at http://www.hindawi.com
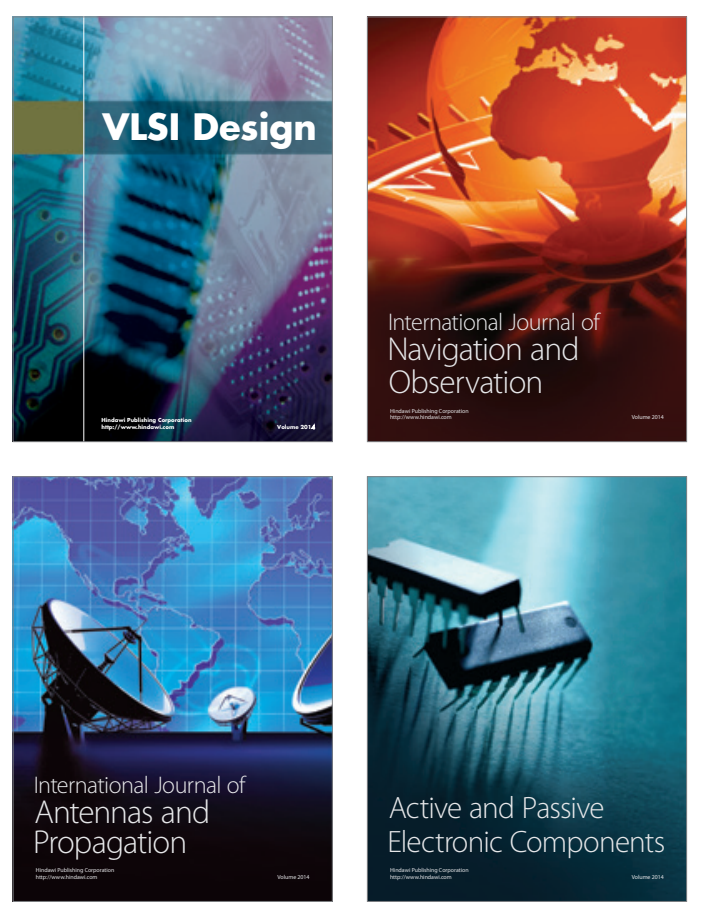
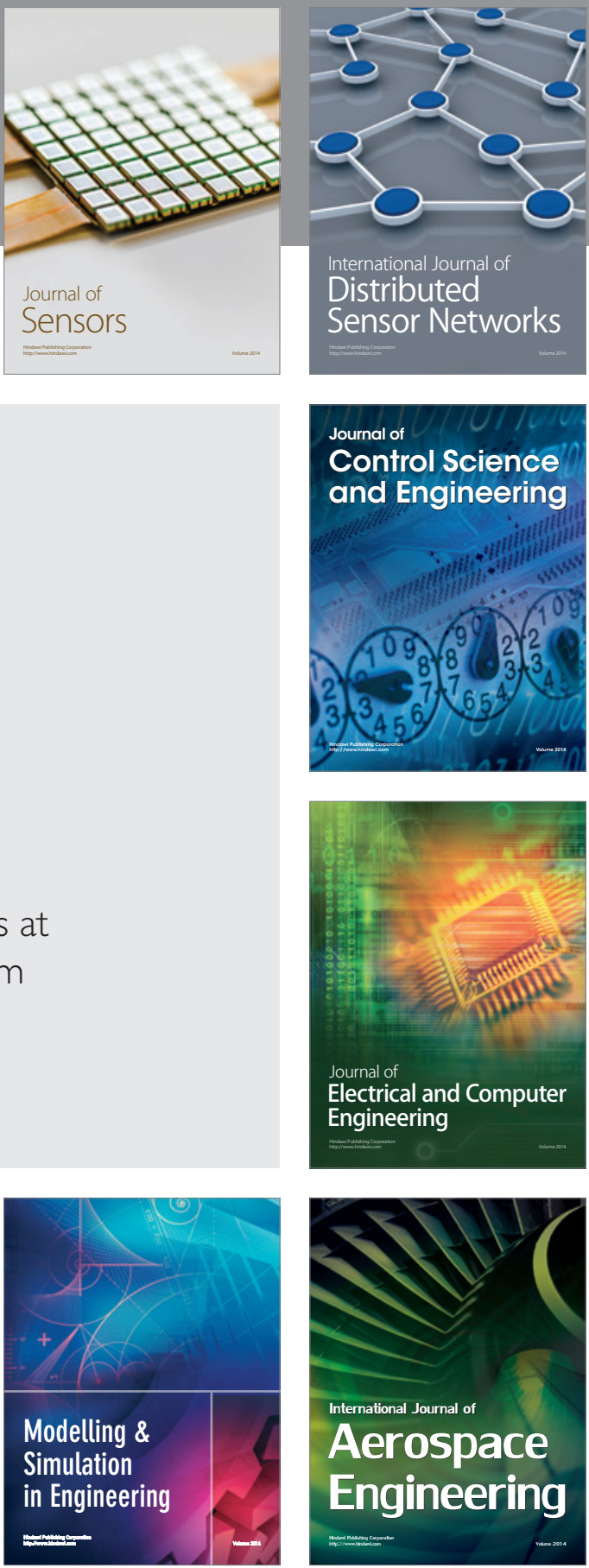

Journal of

Control Science

and Engineering
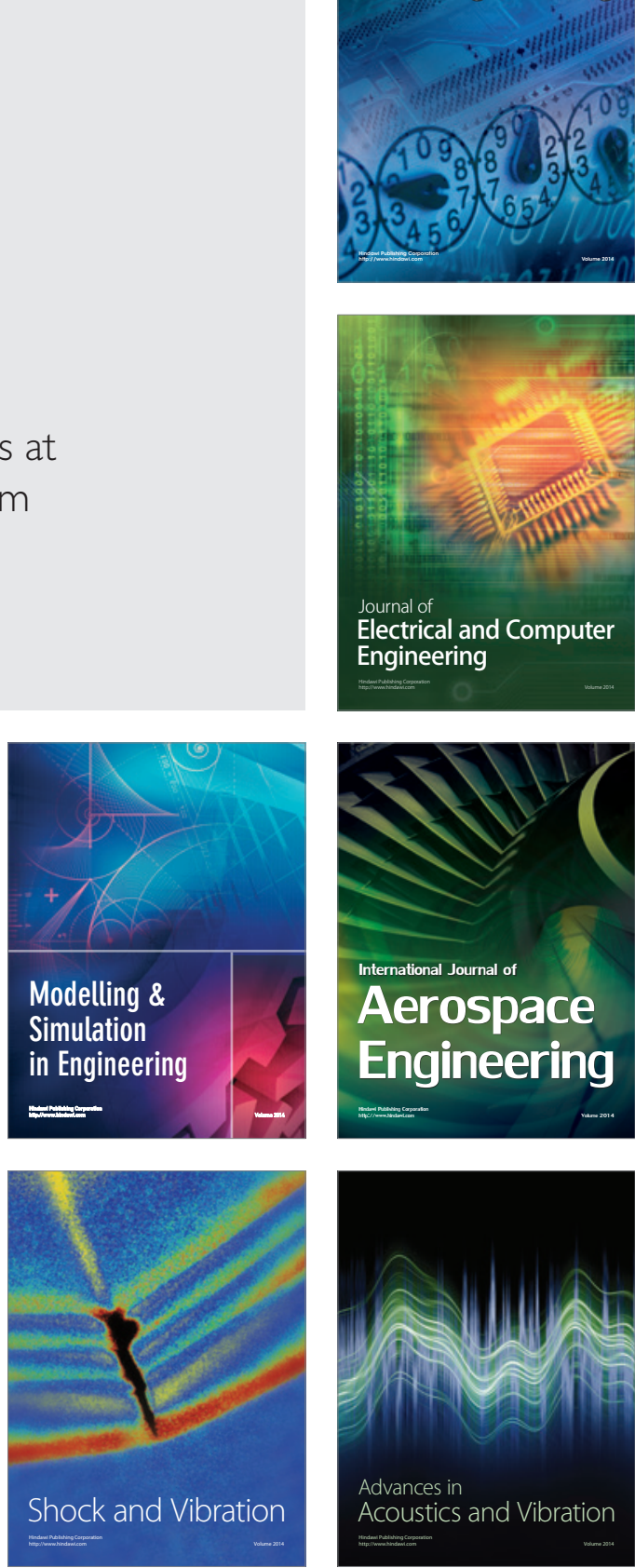